sort; and they all agree that scientific concepts at any epoch are relative and not final.

But all this is not enough. For logical positivists reject as unverifiable, and therefore meaningless, the statement that there is a world independent of all knowers ; while the pragmatists deny that successful practice is a guarantee that the thinking which gaides it must, in order to do so, reflect real features of an independent world. This then is the author's main complaint.

Mr. Cornforth's second complaint is even graver : namely, that in their account of the formation, development and modification of scientific concepts, both logical positivists and pragmatists neglect the influence of the basic processes of human social economic productive activity. This complaint runs "like a red thread" through the whole of the book; and it gives emotional colour to his first complaint. By "divorcing conceptual thinking from the basic processes of human social production" (he says this about Dewey, but it expresses his view about the others as well) and by denying that science can give knowledge of objective reality, they are turning away from the real conditions of modern social life, and evading the real problems of science, that of helping the masses to escape from their exploitation by the capitalists. $\mathrm{H}_{\theta}$ goes further, and claims that their views are an expression of the capitalist outlook, the confusions and self-contradictions which he finds in them mirroring the confusions and self-contradictions of capitalism itself.

The evidence Mr. Cornforth brings for this conclusion seems quite inadequate. However, he writes with clarity, sincerity and candour, and he has great intellectual ability. Though his treatment often results in a distortion of the views he is criticizing, he puts his readers in a position to judge for themselves whether it does so or not. There are many gaps in his presentation of his own views, but he does not try to cover them up, and these are great merits.

The survey is wide, and refers to most of the important writers, Carnap and Dewey being the ones studied at greatest length; and the book may be recommended as a stimulating and provucative commentary, to anyone who is willing to go to the sources for himself. The chapters on dialectical materialism, and on materialism versus idealism, may be commended as an admirable introduction to Marxist philosophy.

L. J. RUSSELI

\section{BRITISH SCIENCE AND TECHNOLOGY SINCE 1851}

A Century of Science, 1851-1951

Written by Specialist Authors under the editorship of Prof. Herbert Dingle. Pp. 338. 15s. net.

A Century of Technology, 1851-1951

Written by Specialist Authors under the Editorship of Dr. Percy Dunsheath. Pp. $346+20$ plates. $15 s$. net.

(London: Hutchinson's Scientific and Technical Publications, 1951.)

Trme HESE two books purport to trace the development of science and of technology during the past hundred years, and to contrast the general position of various branches at the time of the Great Exhibition of 1851 and to-day. They are largely complementary, but there is some technology in the volume on science and much science in that on technology, and to some extent this is due to the divisions adopted.

This is particularly so in "A Century of Science", and moreover it includes at least two chaptersthose on medicine, surgery and their scientific development, and on medical psychology - which could well be regarded as properly belonging to technology. The book includes chapters on the concept of energy, structure of the atom, field physics, particle physics and geology. Prof. J. R. Partington deals with both the structure of molecules and the chemical elements, organic chemistry being discussed in little more than two pages of his second chapter. A chapter on the atmosphere of the earth is followed by one on the constitution and evolution of stars and another on the structure of the universe. Besides chapters on organic evolution, on the coming of man, on the progress of Homo sapiens, and on genetics and embryology, there are others on physiology and histology and on biochemistry, as well as on general psychology, and an essay by the editor, Prof. $H$. Dingle, on the significance of science.

The balance of the book is open to criticism, and this can also be said of the contents of individual chapters. Chemotherapy is inadequately treated in the chapter on medicine and surgery, particularly in comparison with the space given to medical psychology and general psychology. Nor is the balance redressed in "A Century of Technology". Although that volume contains a chapter on biochemical industries in which due emphasis is placed on achievements in the development of antibiotics, only the briefest reference is made to medicinals in Dr. T. I. Williams's chapter on heavy and fine chem. icals. Indeed, the cursory treatment of organic chemistry in the volume on science is paralleled by that given to organic chemical industry in the volume on technology ; no one could gather from either book any idea of the way in which the flowering of organic chemistry in the second half of the nineteenth century led to the development of a great organic chemical industry. The achievements of the dyestuffs industry are indicated more in passing by Dr. $D$. W. Hill in his chapter on textiles than by Dr. Williams, nor, save in the chapter on petroleum technology, do we get a hint of the importance of petroleum as a source of organic chemicals; again, there are no indications of the new importance of acetylene. In any reprint, "Heinrich" should be corrected to "Peter" Griess.

With such reservations, "A Century of Technology" covers technological developments reasonably well, although the emphasis is largely on developments in engineering, and in applied physics it gives a very readable account of many of the outstanding developments of the past hundred years. A well-informed scientist and technologist may find both books useful in giving a ready perspective of the development since 1851 of both seience and technology. It is not, however, easy to decide for whom the books are intended. Both, but especially that on science, seem to assume a knowledge of science and mathematics which the general reader is unlikely to possess. As a contribution to the Festival of Britain, something simpler, better balanced and more carefully planned is required to convey to a general reader a true appreciation of developments in either science or technology, and more especially of the British contribution to such developments.

R. BrightMan 